\title{
Violencia y guerra en el antiguo testamento
}

\author{
Julio Trebolle BarRera */**
}

En décadas anteriores la violencia fue considerada ante todo como un fenómeno social: lucha entre clases sociales, entre pobres y ricos. La violencia social es algo estructural e institucional y sus antinomias son individuo o sociedad, liberalismo o socialismo. En situaciones de violencia social lo religioso puede ser un factor de mantenimiento de estructuras sociales caducas o puede convertirse en fermento revolucionario e impulsor de un cambio social.

Los conflictos bélicos de este fin de siglo, tanto en las sociedades más avanzadas como en los paises del llamado subdesarrollo, están desencadenados por la violencia étnica, la guerra entre pueblos, etnias y tribus. El factor religioso juega aquí un papel todavía más decisivo. En la antigua Yugoslavia se enfrentan, simplificando mucho las cosas, bosnios musulmanes, croatas católicos y serbios ortodoxos. Las guerras de Africa son viejos conflictos tribales, agravados por la violencia social del hambre y la explotación. Las guerras en el Medio Oriente, en el país de la Biblia, la violencia entre árabes y judíos es de raíz y carácter étnico-religioso. No cabe duda de que hunde sus raíces en el Antiguo Testamento y en la religión bíblica de la que proceden tanto el judaísmo como el islam y el cristianismo.

Es frecuente achacar al monoteísmo bíblico y a las religiones monoteístas un talante de intolerancia y de exclusivismo. La conciencia de «pueblo elegido» o de posesión de la verdad religiosa conduce fácilmente a la

* Instituto Universitario de Ciencias de las Religiones. Universidad Complutense de Madrid.

** Ciclo Guerra y Religión en el Próximo Oriente y Egipto. 
violencia de las guerras de religión, a las cruzadas cristianas, a las «guerras santas" proclamadas sin cesar en los paises islámicos, o a la imposición de la ley judía en tierras ocupadas por colonos judíos.

Van der Leeuw distinguía entre «religiones de quietud» o religiones místicas, como el hinduismo y el budismo, y «religiones de combate» 1 . En estas anidan tendencias que consideran la violencia como un medio legitimo de hacer realidad lo que se considera es voluntad divina. Entre estas religiones enumera Van der Leeuw, además de las tres religiones monoteístas, el zoroastrismo, el mitraismo y las religiones germánicas. La reciente violencia en el Punbaj es prueba de que seguramente toda religión lleva en su seno tendencias pacíficas y pacifistas y otras violentas e intolerantes.

La guerra ha sido siempre una «institución natural». Sociedad y ejército eran una misma cosa. En relación con «la guerra de las ciudades» en la Grecia clásica, Jean-Pierre Vernant afirma: «d'une part, l'armée n'est rien, que la cité elle-même; mais d'un autre cote, c' est la cité qui n'est rien qu'une troupe de guerriers" ${ }^{2}$. En los años de la primera guerra mundial e incluso de la segunda y de la guerra civil española, la figura de «Yahvéh guerrero" podía tener todavía carácter ejemplar y modélico. Sólo en época muy reciente se ha producido "un sacudimiento de la seguridad moral de las virtudes bélicas», como afirma Arnold Gehlen: «Puede que las generaciones venideras vean con mayor claridad cómo el interés del capitalismo industrial por los estados de paz - que subrayó con frecuencia Max Weber - se redujo en América a una moral nueva que finalmente llevó, con el Pacto Kellogg de 1928, a que el Derecho internacional proscribiera la «guerra de agresión», usando la expresión outlaw. Por otra parte, las viejas pretensiones socialistas de una clase industrial pacífica apuntaban en la misma dirección. Asi, de dos guerras mundiales y de las ofensivas pacificas del Pacto Kellogg y de los soviets, salió un sacudimiento de la seguridad moral de las virtudes bélicas; hoy, defenderlas en público se ha hecho especialmente difícil en Alemania» ${ }^{3}$.

En las religiones derivadas del Antiguo Testamento y en el propio Antiguo Testamento coexisten dos corrientes contrapuestas: una más propensa a la no violencia y al pacifismo (algunas figuras proféticas, los poverelli, los místicos cristianos o sufíes, etc.), y otra que deriva hacia la

\footnotetext{
1 G. VAN DER LeEUW, Phänomenologie der Religion. Neue Theologische Grundrisse, Tübingen: Mohr, $1956^{2}$.

2 J.-P. VERNANT, «La guerre de cités», Mythe et société en Grèce ancienne, Paris: Éditions La Découverte, 1974, 31-56, cfr. pág. 56.

3 A. GEHLEN, Antropología filosófica. Del encuentro y descubrimiento del hombre por si mismo, Barcelona-Buenos Aires-México: Ediciones Paidós, 1993, pág. 161.
} 
intransigencia, la intolerancia y la violencia al querer convertir en realidad el derecho divino y sacralizar la sociedad.

El judaísmo, el más directo continuador de la letra y del espíritu del Antiguo Testamento, ha desarrollado concepciones y actitudes muy diferentes ante el poder político y la violencia. Un historiador antiguo, Flavio Josefo, y otro moderno, Salo $\mathrm{W}$. Baron ${ }^{4}$ representan un visión del judaísmo según la cual éste nada o poco tiene que ver con la política y el poder político. La historiografía judía representada por Simón Dubnow centra la historia del judaísmo en el mundo de las diásporas sucesivas, marcado por toda una cadena de persecuciones y progroms (la diáspora en Babilonia, en la España medieval, en la cuenca del Rin, Polonia, Rusia, etc.). La corriente historiográfica representada por Ben Zion Dinur y la nueva historiografía israelí destacan el papel central que la tierra de Israel y la idea del Estado judío han representado en la historia del judaísmo. Los historiadores sionistas, siguiendo al filósofo judío Baruc Spinoza, consideran que la religión judía encierra una perspectiva política de la existencia judía y que el judaísmo tiene detrás de sí toda una tradición política y de atención a la dimensión política de la existencia judía.

Estas dos corrientes del judaísmo de todas las épocas, una más política y centrada en la tierra y en el estado de Israel, y otra más orientada hacia la diáspora y alejada de veleidades de poder político, tienen reflejo en dos tendencias contrapuestas y extremas del judaísmo religioso actual. La corriente representada por grupos como Neturei Karta, Edah Haredit, Satmar Hasidim, prolonga una posición tradicional judía caracterizada por un cierto quietismo o pacifismo, que propugna una actitud de aislamiento y de separación respecto a toda forma de estado y de poder, incluido el Estado judío, y espera la redención y el final mesiánico de la historia traído de «lo alto». El sionismo es para estos judíos religiosos una traición al destino y al verdadero ser del judaísmo, pues se arroga una misión sólo propia del Mesias esperado. Por el contrario, la corriente religiosa más celota, representada por el grupo de Gush Emunim o de Meir Kahane, se apropia los logros del sionismo laico, considerando a éste como una etapa en el proceso histórico que conduce inexorablemente a la redención final consistente en la plena independencia de la tierra y del Estado de Israel. Según el midrash, «la tercera redención no será interrumpida». Esta corriente celota trata incluso de ganarle tiempo al mesías, acelerando el curso de la historia mediante un activismo político, que no para mientes ante la lucha violenta ${ }^{5}$.

S.W. BARoN, Historia social y religiosa del pueblo judio, Buenos Aires: Paidós, 1968.

Emmanuel Sivan \& Menachem Friedman, Religious Radicalism and Politics in the Middle East, New York: State University of New York Press, 1990. 
Estas dos corrientes de la historiografía judía no hacen sino prolongar dos tendencias de la propia historiografía bíblica: los textos bíblicos procedentes de la diáspora babilónica (el segundo Isaias de modo particular) muestran un talante más irenista, que los textos escritos en la metrópoli palestina, más cercanos al ideal de un estado monárquico o sacerdotal implantado en la tierra de Israel (la obra cronista).

Lo religioso por si sólo no suele generar violencia política, si no va unido a otros factores étnicos y sociales. Cuando la religión judía, por una parte, y el nacionalismo judío, por otra, se alían para proclamar el carácter sagrado de la tierra y de la nación judías, el conflicto con los vecinos árabes y, sobre todo con los palestinos, parece inevitable. En el Islam ha sido más bien la cuestión de la justicia social y de la distribución equitativa de bienes la que ha generado situaciones revolucionarias contra los poderes constituidos.

La cuestión de la violencia en la Biblia ha provocado siempre en la historia del cristianismo una reacción de rechazo hacia el Antiguo Testamento, desde quienes propugnaban abolir totalmente el Antiguo Testamento y su dios violento e ignorante -marcionitas y gnósticos-, hasta quienes proponían una censura parcial sobre aquellas secciones del Antiguo Testamento que no concuerdan con el espíritu pacifista del Nuevo Testamento, estableciendo de este modo una especie de canon dentro del canon. Las tradiciones de la guerra santa y de la conquista de la tierra prometida figuran entre los textos más violentos de la Biblia y que más repulsa han desatado en la historia del cristianismo y en la época moderna.

Antes de entrar en una consideración filológica, histórica y teológica de los textos del Antiguo Testamento relativos a la cuestión de la violencia, es preciso despejar previamente una serie de prejuicios y de valoraciones globales, que entorpecen la consideración del tema de la violencia en el Antiguo Testamento.

Es muy frecuente oponer la religión bíblica y las religiones vecinas del Antiguo Oriente, bajo el supuesto de que la religión bíblica es una religión de la historia y Yahvéh el Dios de la Historia, mientras que las religiones cananeas y del antiguo Oriente eran religiones de la naturaleza, cuyos dioses dependían de los ciclos de la naturaleza, como el Baal cananeo, dios de la tormenta y de la lluvia, que moría y revivía al ritmo de las estaciones 
anuales. A los dioses de la naturaleza se les supone un carácter fatídico y violento, mientras que el dios de la historia es presentado como un dios que respeta la libertad de los humanos, e interviene en momentos de crisis velando por la salvación de su pueblo.

En un libro importante, History and the Gods, Albrektson ha demostrado que no cabe considerar las religiones del Antiguo Oriente como puras religiones de la naturaleza ${ }^{6}$. Estas conocían también la idea de la intervención de la divinidad en la historia de los pueblos y de las ciudades. Por otra parte, el dios bíblico, Yahvéh, que asumió, historizándolos, todos los caracteres, mitos y ritos, de los dioses astrales de las religiones vecinas, no deja de ser también un dios de la naturaleza. La idea de una contraposición entre religión de la Naturaleza y religión de la Historia o del Espíritu es típica del pensamiento ilustrado y moderno. Por muy sugerente que pueda parecer, no deja de entorpecer el estudio de los textos de las religiones del mundo antiguo y también de la propia religión bíblica. Un examen detenido de los textos del antiguo Oriente muestra que estos conocían también la idea de que los dioses tomaban parte y partido en la vida de los pueblos y en el destino de las ciudades-estado, determinando en definitiva el curso de la historia. Por otra parte, la religión de Israel daba cabida también a la idea de un «decreto" o de un «destino" primordial, escrito en las tablas celestes, que rige desde siempre la naturaleza del cosmos y la historia de los humanos. La Biblia y su mundo circundante cananeo y mesopotámico conocían dos concepciones supuestamente contrapuestas: la visión cíclica y la visión más lineal de la historia, la concepción de la divinidad relacionada con las fuerzas de la naturaleza y la concepción personal de un dios que interviene en la historia.

Otras visiones globales, que pueden parecer no menos sugerentes, resultan igualmente desorientadoras. Un modo bastante común de afrontar el problema de la violencia en el Antiguo Testamento es el de enfrentar al Dios tremendo y violento de la primitiva época mosaica con el Dios, ético y pacifico, del mensaje de los grandes profetas bíblicos, en el momento del máximo esplendor de la religión bíblica. La concepción sobre la historia de Israel de la escuela de Wellhausen lleva implícita esta consideración.

6 Bertil Albrektson, History and the Gods. An Essay on the Idea of Historical Events as Divine Manifestations in the Ancient Near East and in Israel, Coniectanea Biblia - OT Series 1, Lund: Gleerup, 1967. 
Se contrapone igualmente el dios de la monarquía israelita, más cananeizado y de carácter más violento, al dios de los primeros patriarcas y de las tribus israelitas, más genuinamente israelita y de aspecto más pacifico. Tal es la valoración implícita en la reconstrucción histórica y social del antiguo Israel llevada a cabo por Mendenhall y Gottwald, inspiradores de una corriente de estudio sociológico de la Biblia, muy influyente en Estados Unidos ${ }^{7}$. Si es cierto que las tradiciones patriarcales, que reflejan condiciones nómadas y de inferioridad respecto a las ciudades-estado cananeas, ofrecen un carácter pacífico, la promesa de la tierra de Canaán que tales tradiciones transmiten encierra el germen de un conflicto inevitable con la población cananea.

Es frecuente también, y no menos desorientador, oponer el Dios del Sinaí y de la Torah, justiciero y vengador, al Dios del Exodo, libertador de los israelitas de la esclavitud en Egipto. Esta es una dicotomía de raigambre ilustrada, que encuentra eco en la corriente profunda del protestantismo. La separación entre tradiciones del Exodo y tradiciones del Sinaí operada por $\mathrm{G}$. von Rad participa de esta idea ${ }^{8}$.

Cabe explotar también la tensión existente entre el Dios de los sabios de Israel, que intentan superar la violencia por la via de la sabiduría y del conocimiento e incluso del escepticismo, y el Dios de las corrientes y escritos apocalípticos, que esperan la superación de la violencia actual a través de una inminente violencia cósmica y escatológica. Esta dicotomía es la que enfrenta a las teologías de corte liberal y de talante dialéctico.

\section{III}

Pasamos a analizar algunos términos y símbolos que sirven de cauce de expresión de la violencia, así como algunos elementos de la mitología oriental y de la historiografía bíblica que hacen referencia a la violencia y a la guerra ${ }^{9}$.

7 G. MENDENHALL, «The Hebrew conquest of Palestine», Biblical Archeologist 25 (1962) 66-87; N.K. GotTWALD, The Tribes of Yahweh: A Sociology of the Religion of Liberated Israel, 1250-1050 B.C.E., London: SCM Press, 1980 .

8 G. VON RAD, "Das Formgeschichtliche Problem des Hexateuchs», Gesammelte Studien zum Alten Testament 2, Theologische Bücherei 8, München: Kaiser Verlag, 1971, 9-86.

9 Sobre la investigación en torno al tema de la violencia en el Antiguo Testamento, cfr. Norbert LOHFINK, "Gewalt" als Thema alttestamentlicher Forschung», Gewalt und Gewaltlosigkeit im Alten Testament, ed. N. Lohfink, Quaestiones disputatae 96, Freiburg 1983, 15-50. 


\section{Terminología de la violencia}

La raíz 'ph expresa en hebreo la cólera, tanto en sentido físico como anímico y pasional. La antropología bíblica y semita sitúa la sede de la cólera en las narices. En castellano decimos que se le «hinchan a uno las narices» o que va «echando humos», por las narices, se supone. Yahvéh es "lento a la cólera y rico en piedad" (Sal 86,$15 ; 103,8 ; 145,8)$. La expresión «lento a la cólera» traduce la expresión hebrea 'erek 'ap(payim), que literalmente significa «largo de narices» o de «largas narices». Conforme a la simbología de las teofanías cósmicas, el fuego y el humo de la ira divina estaban encerrados en las narices del dios, que en sus explosiones de cólera arrojaba a la tierra sus rayos, truenos y relámpagos. Si las narices del dios eran largas, el fuego y la ira divina podían templarse y descargaban sobre la tierra ya muy enfriados y apagados. Un dios chato era temible, pues sus accesos de cólera eran un exabrupto y una completa descarga.

El verbo 'anaph, "estar enfadado, enfadarse», viene aplicado a Yahvéh en 14 ocasiones. Más frecuente es el uso del sustantivo de la misma raíz, que de un total de 278 usos, es referido a Yahvéh en 183 casos. El dios bíblico manifiesta su cólera con efectos visibles sobre personas y cosas.

El verbo hebreo 'br significa "pasar» $y$, en la forma hitpael, "pasarse», «irritarse». En 8 ocasiones es aplicado a Dios. El sustantivo de la misma raíz, 'brh, es utilizado en el Antiguo Testamento en un total de 34 ocasiones, en 10 de ellas en referencia al hombre y en las 24 restantes hablando de Dios. Está claro que el dios bíblico puede también irritarse.

Al dios bíblico se le aplica el calificativo de «vengador», aunque no en el sentido de "vengativo»: "Dios celoso y vengador es Yahvéh, vengador es Yahvéh e iracundo, vengador es Yahvéh de sus adversarios, y guarda rencor contra sus enemigos. Yahvéh es paciente (literalmente, 'largo de narices')...» (Nahúm 1,1-3); '¡Dios vengador, Yahvéh, Dios vengador, aparece!» (Sal 94,1); "por traje se vistió la venganza, y por manto se envolvió en la indignación» (Is 59,17); «cuando afile el relámpago de mi espada y tome en mi mano la justicia, haré venganza del enemigo y daré su paga al adversario; embriagaré mis flechas en sangre, mi espada devorará la carne; sangre de muertos y cautivos, cabezas de jefes y enemigos" (Dt 32,41-42).

El verbo naqam, "vengar», o niqqem, «vengarse», utilizado en un total de 34 ocasiones, se aplica a Dios en 15 casos; también el sustantivo naqam/neqamah, «venganza», se aplica a Dios en el $80 \%$ de los casos de un total de 44 . Generalmente es el hombre el que habla de la venganza divina $(62 \%)$, pero Dios también anuncia o revela su venganza $(38 \%)$. 
La palabra hebrea y también árabe que designa «violencia» es hoy por todos conocida, hamas, "violencia", el término que un grupo palestino islámico ha tomado como santo y seña de su militancia ${ }^{10}$. Es significativo el hecho de que el verbo hamas, "hacer violencia", "violentar», se aplica en siete ocasiones al hombre y en una sola a Dios, quien destruye con violencia su propio santuario: "Ha violentado, como un huerto, su cabaña, I ha derruido su santuario; ha hecho olvidar Yahvéh en Sión / fiestas y sábados; y ha despreciado en el ardor de su cólera / a rey y a sacerdote" (Lamentaciones 2,6). Yahvéh ejerce la violencia sobre su propio Templo de Jerusalén, destruido en el año 587 a manos de los babilonios, circunstancia que da lugar a aquella lamentación bíblica.

El sustantivo hamas es utilizado 59 veces, siempre en referencia al hombre y nunca a Dios. En el Antiguo Testamento se puede decir y se dice que el hombre es violento, pero no cabe decir que Dios sea violento.

En resumidas cuentas, el Antiguo Testamento presenta la figura de un Dios «irascible» e «irritable», que puede aparecer en sus teofanías con tales características. Sin embargo, el Dios bíblico no admite el calificativo de. "violento", aunque, por otra parte, no deja de anunciar su venganza y de proclamarse celoso cuando la causa de la justicia está en juego ${ }^{11}$.

Para tener una visión más equilibrada sobre los planteamientos de la Biblia en torno a la violencia sería preciso estudiar también los antónimos como "paz», shalom, o «tranquilidad, reposo», menujah, y otros.

\section{Simbología de la violencia}

El «fuego», la llama devoradora, simboliza la teofanía del Dios que hace realidad sus juicios o castigos. El «viento" destructor (cfr. Sal 50,3) tiene también esta misma fuerza simbólica, con matices positivos o negativos. Otros símbolos corrientes y de igual significado son la tormenta, el rayo y el trueno (como fenómeno visual, la «flecha" de Yahvéh, o auditivo,

10 Como interjección puede significar «jViolencia!, ¡socorro!, ¡auxilio!», como en Jeremías 20,8 Habacuc 1,2, y Job 19,7, cfr. L. Alonso ScHöKEL, Diccionario Bíblico Hebreo-Español, Fasc. 3 , Valencia: Institución San Jerónimo, 1990, p. 240.

11 Cfr. artículos de diccionario como los siguientes: G. SAUER, “'af", "Ira"», Diccionario teológico manual del Antiguo testamento (DTMAT), Tomo I, eds. E. Jenni-C. WESTERMANN, Madrid: Cristiandad, 1978, 333-339; H.J. STOEBE, «hãmās, "Violencia"», DTMAT, Tomo I, 810-815; G. SAUER, «nqm, "vengar"», DTMAT, Tomo II, 146-149; E. JOHNSON, «'änaph», Theological Dictionary of the Old Testament (TDOT), I, eds. G.J. Botterweck-H. Ringgren, Grand Rapids, Michigan: W.B. Eeddermans Publishing Company, 1977, 348-360; H. Haag, "chāmās», TDOT 1980, IV, 480-487. 
la "voz» de Yahvéh), y también el diluvio destructor, las tinieblas, el terremoto, la espada y el ángel exterminador, etc. Un oráculo del libro de Isaías reúne muchos de estos símbolos: «Mirad: el Señor en persona viene de lejos, arde su cólera con espesa humareda; sus labios están llenos de furor, su lengua es fuego devorador; su aliento es torrente desbordado que alcanza hasta el cuello: para cribar a los pueblos con criba de exterminio... El Señor hará oir la majestad de su voz, mostrará su brazo que descarga con ira furiosa y llama devoradora, con tormenta y aguacero y pedrisco. A la voz del Señor se acobarda Asiria, golpeada con la vara... Que está preparada hace tiempo en Tofet... una pira con leña abundante: y el soplo del Señor, como torrente de azufre, le prenderá fuego" (Is 30, 27-33) ${ }^{12}$.

Yahvéh hubo de asumir caracteres de Baal, dios de la tormenta y de la fecundidad. Incorporó con ello aspectos teofánicos de carácter violento, propios del dios de la tormenta. De lo contrario, a los ojos de los primeros israelitas venidos del nomadismo, su dios Yahvéh no tendría dominio sobre las lluvias benefactoras, los ciclos de las estaciones, la fecundidad de los campos y la vida agrícola, a la que los israelitas se habrían reconvertido tras su ingreso en la tierra de Canaán. Es sin duda más conforme a la historia reconocer que la mayor parte de los israelitas eran y habian sido siempre cananeos y agricultores y que el dios Yahvéh era también un dios de caracteres cananeos que terminó desplazando a los principales dioses cananeos. Por otra parte, si es cierto que la Naturaleza puede ser violenta, no lo es menos que ofrece también los elementos necesarios para la cultura, la agricultura en primer lugar, y para luchar contra las situaciones naturales o históricas que propician la violencia.

\section{La historiografía bíblica y los relatos de las "guerras de Yahvéh»}

El análisis de los símbolos nos ha llevado ya al terreno de los relatos mitológicos y de la historiografía bíblica y a las narraciones bíblicas sobre la narración de guerras y violencias de las que no carece la Biblia.

A. Huxley pudo afirmar que la exposición pública de los horrores de la guerra acabaría con las guerras. El hecho es que las guerras son hoy televisadas, pero la contemplación directa de la guerra del Golfo o de la

12 Marc GIRARD, “La violence de Dieu dans la Bible juive: approche symbolique et interprétation théologique», Science ef Esprit 39 (1987) 145-170. 
violencia en Bosnia se convierte en un realityshow, que forma también parte de la guerra. La exposición y narración de la violencia forma parte de la violencia misma y del disfrute de la violencia.

La narrativa novelística y la historiografía de todas las épocas, en particular de la clásica grecorromana, encontraron siempre mayor goce estético en relatar la acción (kénesis) de las grandes guerras - griegos contra persas, romanos contra cartagineses, por ejemplo-, que no en exponer los valores tradicionales y las historias ejemplares de las sociedades y de los pueblos. La violencia es más historiable y cinematográfica que la paz. Lo pacífico resulta con frecuencia ñoño, insulso e hipócrita.

Algunos historiadores de la antigüedad, Eforo, Isócrates y Teopompo, rechazaban por razones éticas la descripción detallada y morbosa de acontecimientos violentos. El papel del historiador debía de ser el de relatar acciones ejemplares (paradeígmata), haciéndolo con la mejor calidad estilística. Por el contrario, la escuela helenista de los historiadores «trágicos» criticaba aquella historiografía moralizante, falta de mímesis o realismo y de hedonejo atractivo estético. La viveza del relato exigía describir y exagerar incluso la violencia, para suscitar así la piedad y el horror de los lectores. Polibio criticó esta tendencia a la dramatización, exigiendo el debido respeto a la verdad de los hechos ${ }^{13}$.

La Biblia no ofrece verdaderos relatos de batallas. Los únicos elementos reseñables de una batalla son los preparativos -el envio de espías para inspeccionar el campo enemigo-, y el desenlace, la aplicación del jerem o exterminio ritual del botín. En los relatos más antiguos se reseña la emboscada tendida para obligar al enemigo a salir de la ciudad sitiada. Estos tres elementos, espionaje, emboscada y jerem, son característicos del género narrativo de «guerra santa». La «guerra de Yahvéh» está ganada o perdida de antemano, sin intervención significativa del ejército. Los espias vuelven diciendo que "Yahvéh ha entregado a los enemigos en vuestras manos" y los israelitas no tienen más que recoger los despojos de la batalla, observando escrupulosamente las leyes sobre un botín que pertenece a Yahvéh, vencedor único de la batalla. Ello hace supérflua toda descripción de las escenas de guerra.

En la narrativa bíblica la violencia no es un elemento literario (estético) o histórico (verdadero) como lo es en la literatura clásica. La violencia es un factor religioso de reinstauración de la justicia violada. La figura de

\footnotetext{
13 Viktor D'HuYs, «How to Describe Violence in Historical Narrative. Reflections of the Ancient Greek Historians and their Ancient Critics», Ancient Society 18 (1977) 209-250.
} 
Yahvéh "guerrero divino" es la del luchador por la justicia. En la época de los Jueces-libertadores, las tribus israelitas consideraban a Yahvéh como el único Juez y Libertador, que defendía, si era preciso con la guerra, la causa de la justicia, tanto en las relaciones entre tribus como en las relaciones de Israel con los otros pueblos. Más tarde se desarrolló toda una ideología de la guerra santa, que si en un principio se utilizaba contra los pueblos vecinos, con los profetas se volvió en amenaza contra el propio pueblo de Israel, amenazado de extermino por su continua infidelidad a Yahvéh.

En la mitología del Antiguo Oriente la violencia entre los humanos es consecuencia y remedo de las guerras entre los dioses. Los dioses nacian y perecían por guerras intestinas, por la violencia que anidaba en el ser mismo de los dioses. Los mitos mesopotámicos atribuían el origen y el ser violento de los humanos a una rebelión y a un crimen primordial entre los dioses. La sangre del dios rebelde Kingu fue mezclada con la tierra para formar al hombre, creado para servir a los dioses. El hombre es hijo, pues, de un crimen y de una violencia primordial, es violento y víctima a la vez de la violencia. Puede echar la culpa a los dioses, pero no le queda más salida que la resignación y el fatalismo. Las religiones orientales y de modo especial la cananea repartían la responsabilidad del gobierno de cielos y tierra entre un dios supremo, creador y padre de los dioses, convertido en un viejo dios ocioso, ' $\mathrm{El}$, y un dios joven, activo y violento, $B a^{\prime} a l$, responsable de la conservación de lo creado. La figura del dios bíblico, Yahvéh, asumió con relativa facilidad gran parte de la simbología del dios supremo El/Elohim; rechazó con empeño y celo muchos de los caracteres del dios Baal, pero no dejó de asumir algunos de los caracteres del "guerrero divino» ${ }^{14}$.

\section{IV}

La Biblia desmitologiza la guerra, sacralizándola en un primer momento, para luego despojarla también de este carácter sagrado.

Dos son los modos habituales de enfrentar la cuestión de la «guerra santa» en Israel.

El primero acentúa los caracteres distintivos de la guerra santa en Israel, sin prestar especial atención a las ideas que sobre la guerra pudieran tener

14 F.M. Cross, Canaanite Myth and Hebrew Epic. Essays in the History of the Religion of Israel, Cambridge MA: Harvard University Press, 1973, 145-194. 
los pueblos vecinos. Según este modo de ver, el carácter religioso y el desenlace milagroso propio de la guerra santa - la victoria de Israel gracias a la intervención de Yahvéh sin intervención apenas del ejército israelita-, son fruto de una interpretación teológica de época posterior ${ }^{15}$.

La segunda posición considera que la ideología y la institución de la guerra santa eran patrimonio común de todos los pueblos del Antiguo Oriente antes y después de que naciera Israel. El carácter religioso y milagroso de la guerra es un elemento constitutivo de la propia concepción de la guerra y no el fruto de una interpretación posterior (R. Smend, M. Weippert, cfr. infra).

Quienes acentúan los caracteres distintivos de la guerra santa en el antiguo Israel señalan, por ejemplo, que conforme a los textos bíblicos los israelitas no precisaban luchar o que el ataque se producía por sorpresa. G. Von Rad ha estudiado los elementos formales de los relatos de guerra santa en el antiguo Israel ${ }^{16}$. Estos son básicamente los siguientes: la guerra santa es convocada mediante el sonar de las trompetas (Jue 6,34s.) o el envío de los miembros descuartizados de un animal a las diferentes tribus (I Sam 11,7); la milicia es consagrada a Yahvéh ('am yhwh, Jue 5,11, Jos 3,5$)$; se ofrecen sacrificios antes de la batalla y se consulta el oráculo de Yahvéh (Jue 20,23.26); la respuesta favorable se produce bajo la fórmula "Yahvéh ha entregado al enemigo en vuestras manos" (Jos 2,24); Yahvéh mismo parte al campo de batalla (Jue 4,14); el alarido de guerra señala el inicio de la batalla (teru'a, Jue 7,20$)$; Yahvéh interviene en todo momento (Jos 10,10 ; Jue 4,15 ) y es quien vence (Jue 5,31 ) y aterroriza al enemigo (Jos 2,8.24); la batalla concluye con el exterminio o jerem, exterminio de hombres y animales y consagración del botín, plata, oro y demás despojos (Jos 6,18-19); la milicia de Yahvéh se disuelve y regresa a sus tiendas (Jue 20,8). Ningun relato contiene la totalidad de estos elementos ni tampoco por el orden señalado. Según Von Rad, los relatos de guerra santa tienen su ambiente de origen y desarrollo (Sitz im Leben) en la anfictionía de las tribus. Era una institución y actividad de la confederación tribal. Se trataba de guerras defensivas, muy diferentes de las guerras ofensivas de la época monárquica posterior.

El carácter anfictiónico de la guerra santa, defendido por Von Rad, ha sido puesto en cuestión por Smend y otros ${ }^{17}$. También ha sido objeto de

15 Sa-Moon Kang, Divine War in the Old Testament and in the Ancient Near East, BZAW 177, Berlin-New York: Walter de Gruyter, 1989.

16 G. VON RAD, Der Heilige Krieg im alten Israel, Zurich: Zwingli-Verlag, 1951.

17 R. SMEND, Yahwekrieg und Stämmebund. Erwägungen zur âitesten Geschichte Israels, Göttingen: Vandenhoeck \& Ruprecht, 1963. 
crítica la reducción de la guerra santa al período de las tribus, así como la distinción entre guerras defensivas y ofensivas. La guerra santa era una institución vigente en la época posterior, davídica y monárquica, y bien conocida, por otra parte, en todo el Antiguo Oriente (Weippert) ${ }^{18}$. Se puede hablar de la Guerra de Ishtar o de la Guerra de Ninurta con igual derecho que se habla de la Guerra de Yahvéh. En Egipto Ugarit, Mari y en los reinos hititas y neoasirios las guerras nacionales eran consideradas guerras santas ${ }^{19}$. Los dioses nacionales vigilaban y decidían el curso y el éxito de las guerras. Asi, «Enlil no permitió a nadie hacer frente a Sargon» (ANET 267b) y, como reconoce el rey de Moab, Mesha, Kemosh «me salvó de todos los reyes y me hizo triunfar sobre todos mis adversarios" (ANET 320b). Determinados dioses cumplían de modo especial esta función: Nergal era el rey de la batalla e Ishtar la diosa de la guerra, Baal era el dios guerrero cananeo, etc.

Determinadas características de los preparativos, decurso y conclusión de las guerras nacionales ponen de relieve su carácter de guerra santa. Antes de la batalla el rey visitaba el santuario de los dioses, ordenaba ofrecer sacrificios a los dioses en las fronteras del territorio enemigo (ANET 354b 355a), se hacian consultas a los adivinos, se observaba el curso de la luna y de las estrellas, y se trataba de conocer cuáles eran los días y meses favorables para la batalla. Para asegurar la presencia del dios en el decurso de la batalla se utilizaban estandartes (ANET 270a), se suponía que era el mismo dios quien hacia entrega de las armas al rey, que los dioses marchaban y luchaban al lado del rey (ANET 289b; 300a) y eran ellos quienes decidian el éxito de la guerra (ANET 281b), volviendo locos a los enemigos (ANET 289b). Después de la batalla se ofrecían sacrificios de acción de gracias (ANET 276b, 278a); los hititas celebraban una fiesta en honor del dios guerrero (ANET 358ss); se erigían estelas en el territorio enemigo con inscripciones apropiadas (ANET 293a) y templos conmemorativos; se componían y entonaban himnos de victoria (ANET 376ss; 373ss.), etc.

Cross y Miller han puesto de relieve la pervivencia de caracteres mitológicos en los relatos de guerra santa en Israel, que son ignorados por Von $\operatorname{Rad}^{20}$. Insisten en la continuidad que existe entre la figura de Yahvéh

18 M. WEIPPERT, «"Heiliger Krieg" in Israel und Assyrien. Kritische Anmerkungen zu Gerhard von Rads Konzept des 'Heiligen Krieges im alten Israel»', ZAW 84 (1972) 460-493.

19 G.H. JONES, "The concept of holy war», The World of Ancient Israel. Sociological, Anthropological and Political Perspectives, ed. R.E. Clements, Cambridge: Cambrige University Press, 1989, 299-321.

20 P.D. Miller, The Divine Warrior in Early Israel, Harvard Semitic Monographs 5, Cambridge MA 1973 
guerrero y la correspondiente figura del Baal cananeo. Cross ha mostrado cómo la guerra santa representa el eslabón que hizo posible la transición del culto de las tribus al culto de la monarquía: la presencia de elementos cósmicos en las tradiciones antiguas sobre la guerra santa (Jue 5,20.23; Jos 10,12.13), facilitó la mitologización de la conquista de Canaán tras la instauración de la monarquía y la construcción del templo. La guerra santa contribuyó también a facilitar más tarde la transición al mundo de ideas de la apocalíptica posterior (cfr. el «Libro de la guerra de los hijos de la luz y los hijos de las tinieblas») ${ }^{21}$.

La historia de la guerra santa es muy compleja y pone en juego perspectivas muy diferentes, que giran en torno al carácter militar, cultural o sacerdotal, y carismático o profético de la guerra santa.

En un comienzo la guerra santa era un tipo de guerra corriente y habitual en todo el Oriente Antiguo. Lo religioso y lo profano iban de la mano. Se trataba de hechos de guerra o de hazañas de héroes guerreros tan habituales como el asesinato político llevado a cabo por Ehud (Jueces 3). El relato era ampliado más tarde conforme al modelo de guerra santa. Asi al relato primitivo de Ehud le fue añadido el texto correspondiente a Jue $3,15 b-26$, que hace de una hazaña aislada todo un relato de guerra santa. El hecho de que no cupiera distinguir entre guerras profanas y santas daba lugar a que guerras de carácter absolutamente profano pasaran a convertirse en guerras santas y sus héroes en salvadores del pueblo en nombre de Yahvéh. La guerra de Yahvéh era reconocida como tal a posteriori, ex eventu. Este evento era una conjunción afortunada de la acción de elementos naturales y de la acción de los héroes. De una manera u otra caemos siempre en el dilema de considerar la guerra como un fenómeno «natural» o como una institución «sagrada». Cabe acentuar, como hacen Von Rad y de forma más sutil $W$. Richter ${ }^{22}$, el aspecto religioso de las guerras bíblicas y decir que la guerra santa se desarrollaba como una verdadera institución de culto, de modo que el esquema formal, líterario y teológico, desarrollado plenamente en una época posterior era un buen reflejo de lo que era y había sido siempre en realidad la guerra. Otros, como Smend en la obra antes citada, opinan que la guerra santa no existió nunca como tal; no es más que una construcción teológica tardía, elevada sobre lo que era un fenómeno natural conocido en todo el Oriente Antiguo. Sin embargo, la guerra revestía también un carácter sagrado en

21 F.M. CRoss, Canaanite Myth and Hebrew Epic, (1973), 326 ss.

22. W. RICHTER, Traditionsgeschichtiche Untersuchungen zum Richterbuch, Bonner Biblische Beitrage 18, Bonn: Hanstein, 1963. 
las religiones del antiguo Oriente próximo, con lo que caemos de nuevo en un dilema al que es difícil encontrar solución, si no es tratando de evitar el dilema mismo y de no establecer una dicotomía excesiva entre la realidad de la guerra, por una parte, y la interpretación literaria y teológica de la misma, por otra. La guerra era considerada desde un comienzo como verdadera guerra de Yahvéh, como podía serlo de Baal o de Kemosh. Los desarrollos literarios y teológicos posteriores no hicieron más que acenturar el carácter de culto de la guerra. Realidad e ideología se condicionaban mutuamente. Relatos de guerras de la época monárquica, como la relatada en 1 Re 20 y las guerras arameas, muestran cómo la teoría determinaba la práctica de la guerra santa.

Si es cierto que la forma más antigua de los relatos de guerra tenía un carácter simplemente militar y guerrero, con el paso del tiempo su forma fue remodelada conforme a modelos culturales por una parte y proféticos por otra.

El modelo cultual o sacerdotal se reconoce sobre todo en la exhortación e instrucción que precede a la guerra, en la que Yahvéh por sí mismo o a través de sus sacerdotes da el sentido de la batalla posterior. Este modelo es fácilmente reconocible en la forma de los relatos de Ex 14, Jos 10 y Jue 4 y 1 Sam 7.

El modelo profético pone el acento en el hecho de que el héroe del combate actúa arrebatado por el espíritu de Yahvéh. Este nuevo modelo se desarrolla en la época profética y revela un ambiente dominado por el prestigio de figuras carismáticas y proféticas. Aparece reflejado en los relatos de 1 Sam 11 y Jue 3 y 6 s. La teorización y formulación literaria de «la guerra santa» se opera en este contexto de exaltación carismática y de animosidad antimonárquica, que precede a la época y a la obra de la escuela deuteronómica ${ }^{23}$.

La concepción carismática y profética de la «guerra santa» responde a un intento de estructuración política y religiosa del antiguo Israel, en la que el personaje decisivo no es ya el rey guerrero, sino el profeta, garante del derecho del único rey, Yahvéh.

Esta concepción hace de los israelitas un pueblo sin armas, cuyas guerras son sólo de liberación y cuyas victorias son milagros de Yahvéh. El profeta predica la neutralidad, frente al rey y al sabio-consejero, que quieren

23 W. Richter, Die Bearbeitungen des "Retterbuches" in der deuteronomischen Epoche, Bonner Biblische Beitrage 21, Bonn: Hanstein, 1964. 
contemporizar con las grandes potencias y armarse adecuadamente para los casos de conflicto. Hace del Profeta, prefigurado en el mismo Moisés, la figura central y más genuina de Israel, a expensas de las figuras del Rey y del Sabio-consejero, que propugnan una política de defensa y de agresión si es preciso. Considera la monarquía como una institución extraña e impuesta en Israel: "Se nombraron reyes sin contar conmigo..." $(O s 8,4)$. El Deuteronomio reduce la capacidad de acción del rey, obligado al cumplimiento estricto de la Ley (Dt $17,14-20$ ) .

Los grandes profetas fueron más allá al dirigir el concepto de guerra santa contra el propio Israel. Los oráculos contra las naciones extranjeras del libro de Amós (1-3) incluyen un oráculo contra el reino de Israel. Miqueas y Jeremías hablan de una guerra de Yahvéh contra su propio pueblo (Miq 3,5; Jer 6,1-6; 22,7). Yahvéh no combate esta vez al lado de Israel, haciendo milagros contra los enemigos de Israel, sino al lado de las potencias que oprimen a Israel (Is 42,13-16; 45,1-8) (M.C. Lind).

En el final de la historia bíblica la obra del Cronista (Libros de las Crónicas, en relación con los libros de Esdras y Nehemias) toma como modelo del programa de restauración tras el exilio la comunidad de los primeros tiempos, antes del establecimiento de la monarquía, saltándose de este modo el período central de la historia de Israel. El Cronista aspira a la utopía de una sociedad de hermanos, una sociedad sin rey, una «anarquía regulada» ${ }^{24}$. La terminología del Cronista muestra su interés por la «paz» y la «guerra», más por aquella que por ésta. La guerra, miljamah, es siempre una guerra exterior y de autodefensa. Es, por otra parte, una guerra histórica, desprovista de caracteres cósmicos o escatológicos. El Cronista desacraliza y desmitologiza la guerra. La terminología relativa a la paz es más rica y significativa (šlom, «paz»; šeqet, «tranquilidad", menujah, "descanso", etc) que la concerniente a la guerra. Su vocabulario no es de triunfo y victoria, sino de «salvación» y «liberación» 25.

Este rápido repaso a las diferentes concepciones sobre la guerra santa en el antiguo Israel quedaría incompleto sin una breve referencia a los desarrollos más tardíos del periodo bíblico, que tienen reflejo, por una parte, en la versión de los Setenta, una obra representativa del punto de vista de la diáspora judía, de tendencias más pacifistas, y, por otra, en textos de la comunidad esenia de Qumrán, representativos de una corriente radicada en la propia metrópoli judía y más radicalizada en lo ideológico.

24 Christa SCHÄFER-LICHTENBERGER, «Gesellschaft ohne Herrschaft-Historie und Utopie in der Geschichte Israels», Freude am Gottesdienst. Festschrift für Frieder Schulz, Heidelberg $1988,489$.

25 J.P. WEINBERG, «Krieg und Frieden im Weltbild des Chronisten», Orientalia Lovaniensia Periodica 16 (1985) 111-129. 
Es curioso observar cómo la versión de los LXX corrige el sentido de aquellos pasajes que presentan a Yahvéh como "guerrero», traduciendo este término por la expresión "(Yahvéh), el que destruye la guerra» (Ex $15,3$; Is 42,13 ; Jue 9,$7 ; 16,3)$. En un pasaje de Miqueas $(2,8)$ la versión griega interpola incluso la expresión «destrucción de la guerra». En Oseas $(2,20)$ la referencia a la destrucción de las armas de guerra aparece convertida en referencia a la destrucción de la guerra misma (cfr. igualmente, Filón, Praem 91 y 93).

Llaman la atención, por el contrario, expresiones como «jAlzate, Guerrero!, iToma tus cautivos, Hombre de gloria! ", que se encuentran en el libro de la "Guerra de los hijos de la luz contra los hijos de las tinieblas». Frente a la concepción nacionalista y étnica de la guerra propia de escritos bíblicos anteriores, este libro de Qumrán inaugura, según J. Collins, una concepción de la guerra basada en un enfrentamiento de carácter moral y cósmico entre las fuerzas de la luz y de las tinieblas ${ }^{26}$. El autor de esta obra, que parece haber utilizado un manual romano del arte de la guerra para sus descripciones de la guerra apocalíptica, expresa las ideas del grupo esenio de Qumrán, cuyos últimos miembros pudieron haber tomado parte en la revuelta armada contra los romanos en el año $70 \mathrm{~d}$. C.

No era posible ni se pretendía tratar aquí todos los aspectos que inciden en el tema de la "Violencia en el Antiguo Testamento" y no hemos tocado para nada los relativos a la "No violencia» en la Biblia. Baste decir, para terminar, que la ideología de la "guerra santa» sufrió un proceso de reconversión y de crítica a manos de los profetas bíblicos, que, como Isaías, proponían una neutralidad política y el convertir las armas en instrumentos de labranza. Al mismo tiempo el monoteísmo o monoyahvismo de los profetas era susceptible de una interpretación celota e intolerante, que no ha dejado de mostrarse en erupciones de celotismo y de violencia religiosa a lo largo de los siglos en las tres religiones monoteístas.

26 J. Collins, "The Mythology of Holy War in Daniel and the Qumran War Scroll», VT 25 (1975) 596-612, pág. 609. 